\title{
RELAÇÃO ENTRE ATRIBUTOS DO TERRENO, MATERIAL DE ORIGEM E SOLOS EM UMA ÁREA NO NOROESTE DO ESTADO DO RIO DE JANEIRO
}

\section{Relationship between terrain attributes, parent material and soils in an area in the Northwest of Rio de Janeiro State (Brazil)}

\author{
Cesar da Silva Chagas \\ Embrapa Solos, Rio de Janeiro \\ chagas.rj@gmail.com \\ Elpídio Inácio Fernandes Filho \\ Prof. Adjunto, Depto. Solos, Universidade Federal de Viçosa. Bolsista CNPq \\ elpidio@ufv.br \\ Silvio Barge Bhering \\ Embrapa Solos, Rio de Janeiro \\ silvio@cnps.embrapa.br
}

Artigo recebido em 17/07/2012 e aceito para publicação em 13/09/2012

RESUMO: O presente estudo teve como objetivo identificar as relações existentes entre atributos do terreno, material de origem e os solos em uma área no Noroeste do Estado do Rio de Janeiro. Os atributos do terreno: elevação, declividade, aspecto, plano de curvatura, radiação solar e índice CTI, e as litologias dominantes na área tiveram influência direta na distribuição dos solos da área, com os solos derivados de migmatitos apresentando mudança textural abrupta, diferentemente dos solos originados dos granulitos. A elevação e a declividade ajudaram a explicar a distribuição dos Neossolos Litólicos e Cambissolos na área, enquanto a declividade e o índice CTI explicam a ocorrência dos Argissolos Amarelos, Vermelho-Amarelos e dos Gleissolos em relevo suavizado. Diferenças na profundidade são condicionadas pela curvatura do terreno, com áreas côncavas apresentando solos menos profundos (saprolíticos) do que nas áreas convexas. Os Argissolos derivados dos granulitos, que ocorrem em relevo forte ondulado ou montanhoso, em encostas voltadas para norte, com maior incidência de radiação solar, apresentam coloração vermelha e são eutróficos, enquanto os Argissolos das encostas voltadas para sul (< radiação solar) são vermelho-amarelados, distróficos e com horizonte B latossólico em profundidade.

Palavras-chave: relação solo-paisagem, mapeamento digital de solos, pedometria.

ABSTRACT: The present study aimed to identify the relationships between land attributes, source material and soils in a Northwest Rio de Janeiro State area. Land attributes as: elevation, slope, aspect, plan curvature, solar radiation and compound topographic index (CTI), and the dominant lithology in the area had a strict influence on the soil distribution, which that ones derived from migmatites showing abrupt textural change, unlike soils originating from the granulites. Elevation and slope attributes helped out to explain the distribution of Leptosols and Cambisols in the area, while slope and CTI attributes explain the occurrence of Yelow and Red Yelow Acrisols and Gleysols on low relief. Distincts depths are constrained by the curvature of the terrain, with concave areas presenting shallower soils (saprolitic) than in convex areas. The Acrisols derived from granulites, which occur in hilly conditions, on slopes facing north and highest incidence of solar radiation, show red hue and are eutrophic, while the Acrisols on slopes facing south ( $<$ solar radiation) are yellowish-red, dystrophic and show ferralic horizon at depth.

Keywords: soil-landscape relationships, digital soil mapping, pedometrics. 


\section{INTRODUÇÃO}

A topografia do terreno exerce enorme controle sobre os processos hidrológicos superficiais e sobre os ecossistemas, influenciando a radiação solar, precipitação, escoamento superficial, evaporação, regime de umidade do solo e tipo de vegetação. As condições de energia e fluxo de massa influenciam os tipos de vegetação e sua sucessão e estes fluxos são afetados pela topografia através da influência combinada da elevação, declividade, orientação e rugosidade do terreno. Os parâmetros topográficos determinam a exposição de uma paisagem, condicionando, assim, seu microclima (DIXON, 1995).

Por sua vez, o solo controla as transferências e transformações de sólidos, líquidos, gases, bem como de energia, e assim sendo, o conhecimento sobre a sua distribuição espacial é de fundamental importância. A recente e crescente preocupação ambiental tem renovado a necessidade pelos inventários de solos, visto que a informação sobre este recurso natural é necessária, entre outros, para promover o aumento da produtividade e mitigar os danos ambientais.

Muitos estudos têm buscado correlacionar observações ou medições do solo com uma variável auxiliar cuja distribuição espacial pode ser mais facilmente obtida. Uma grande atenção tem sido dada para relação entre propriedades do solo e o relevo, devido ao seu conhecido papel como fator de formação do solo (CHAPLOT et al., 1998; FLORINSKY \& KURYAKOVA, 1998; MCKENZIE \& RYAN, 1999; GESSLER et al, 2000; LAGACHERIE \& VOLTZ, 2000) e a ampla disponibilidade de modelos digitais de elevação (MDEs) utilizados para derivar atributos do terreno (GARBRECHT et al., 2001).

Um modelo digital do terreno, também referido como modelo digital de elevação é definido como qualquer representação quantitativa digital da variação contínua do relevo sobre o espaço, ou seja, um mapa de elevação, que pode ser utilizado para derivar diferentes atributos topográficos (WILSON \& GALLANT, 2000).

Para Moore et al. (1993), os levantamentos de solos podem ser melhorados através da utilização de atributos do terreno derivados de um MDE, fornecendo, assim, um método para geração de mapas de alta resolução, os quais são potencialmente importantes, pois possibilitam a identificação de aspectos da superfície do terreno que são difíceis de serem notados na interpretação de fotografias aéreas tradicionais.

Os atributos do terreno podem ser divididos em atributos primários ou secundários (compostos), sendo os atributos primários diretamente calculados a partir do MDE e incluem variáveis como: elevação, declividade, aspecto, plano e perfil de curvatura, comprimento do caminho do fluxo e área específica de contribuição (GALLANT \& WILSON, 2000). A elevação, declividade e aspecto, têm sido reconhecidos como os mais efetivos para a realização de levantamentos de solos de média escala (extensivos).

Um dos primeiros estudos a utilizar atributos ambientais para a predição do solo foi realizado por Troeh (1964), que analisou dados de elevação de duas catenas para derivar a declividade e perfil de curvatura. A partir destas informações ele observou que as classes de drenagem do solo poderiam ser estimadas através de uma equação.

Muitos pesquisadores têm encontrado em seus estudos relações estatísticas satisfatórias entre atributos do terreno facilmente derivados de um MDE e diferentes atributos dos solos. Segundo Gessler et al. (2000) os modelos que utilizam apenas o índice topográfico combinado $(\mathrm{CTI})$ poderiam responder por 84 e $71 \%$ da variação da profundidade do solo e da profundidade do horizonte A, respectivamente. Pachepsky et al. (2001) indicaram que a declividade, a curvatura tangencial e o perfil de curvatura são bons indicadores da textura do solo, e explicaram mais de $60 \%$ das variações do teor de umidade do solo em 10 e $33 \mathrm{kPa}$. Ziadat (2005) utilizou a declividade, perfil de curvatura, plano de curvatura, curvatura média, aspecto e área de contribuição para predição de atributos do solo e encontrou correlação satisfatória com a profundidade do solo, a capacidade de armazenamento de água e a textura do solo, entre outros atributos.

No Brasil, tratando-se de classes de solos mais especificamente, Ippoliti et al. (2005) derivaram, a partir de um MDE, os atributos do terreno elevação, declividade e curvatura que foram posteriormente utilizados no delineamento de pedoformas na região de Viçosa (MG). Neste estudo foi obtida uma exatidão global de 72 \% na classificação das formas da paisa- 
gem e boa correlação entre as classes obtidas com as classes de solos dominantes. Segundo os autores, a abordagem utilizada mostrou-se uma alternativa rápida e econômica em comparação ao delineamento manual a partir da utilização de análise estereoscópica de fotografias aéreas.

Sousa Junior \& Demattê (2008) utilizaram um modelo digital de elevação para derivar mapas de elevação e declividade com o objetivo de caracterizar unidades de mapeamento de solos das regiões de Ibaté e São Carlos (SP) desenvolvidos de materiais basálticos e areníticos. A incidência dos solos em suas respectivas classes de declive e altitude foi determinada, mostrando que cada solo apresentou comportamento diferenciado em relação, principalmente, às classes de declive. O estudo concluiu que o conhecimento da distribuição dos solos no relevo é de grande importância, pois facilita a execução do levantamento de solos e que o MDE utilizado apresenta semelhanças com o mapa de solos, podendo auxiliar na sua execução.

Levando em consideração a importância do material de origem e do relevo na formação dos solos, este trabalho teve como objetivo avaliar a influência do material de origem e dos atributos do terreno derivados de um MDE na distribuição dos solos em uma bacia hidrográfica na região Noroeste do Estado do Rio de Janeiro. Esta bacia representa uma área dissecada típica dos Mares de Morros, onde se encontra grande diversidade litológica e condições climáticas sazonais.

\section{MATERIAL E MÉTODOS}

A área estudada, de aproximadamente 10.000 ha, compreende uma parte da bacia hidrográfica do rio São Domingos, afluente do rio Muriaé, no município de São José de Ubá, Noroeste do Estado do Rio de Janeiro (Figura 1), situada entre as coordenadas UTM 7.628 .602 e $7.638 .232 \mathrm{mN}$ e 186.178 e $196.048 \mathrm{mE}$, zona $24 \mathrm{~S}$.

A bacia do rio São Domingos apresenta, de acordo com a classificação climática de Köppen, clima do tipo Aw (clima tropical, com inverno seco), com estação chuvosa no verão, de novembro a abril, e nítida estação seca no inverno, de maio a outubro. A temperatura média do mês mais frio é superior a $18^{\circ} \mathrm{Ce}$ as precipitações são superiores a $750 \mathrm{~mm}$ anuais, atin- gindo $1800 \mathrm{~mm}$. As litologias predominantes na área, segundo DRM (1980), são: granulitos noríticos da Unidade São José de Ubá (60\%); migmatitos das Unidades Catalunha, São João do Paraíso e Vista Alegre (29,7\%); e Sedimentos Aluvionares do Quaternário (9\%). Dois sistemas de relevo são encontrados na área: o Domínio Colinoso de Mar de Morros, caracterizado por apresentar amplitude topográfica inferior a 100 m; e os Alinhamentos Serranos e Degraus Estruturais (NE-SW), caracterizados por imponentes elevações de grande amplitude de relevo com vertentes íngremes e escarpadas, por vezes rochosas, de altos gradientes e topos aguçados de cristas alinhadas (DANTAS, 2000). 


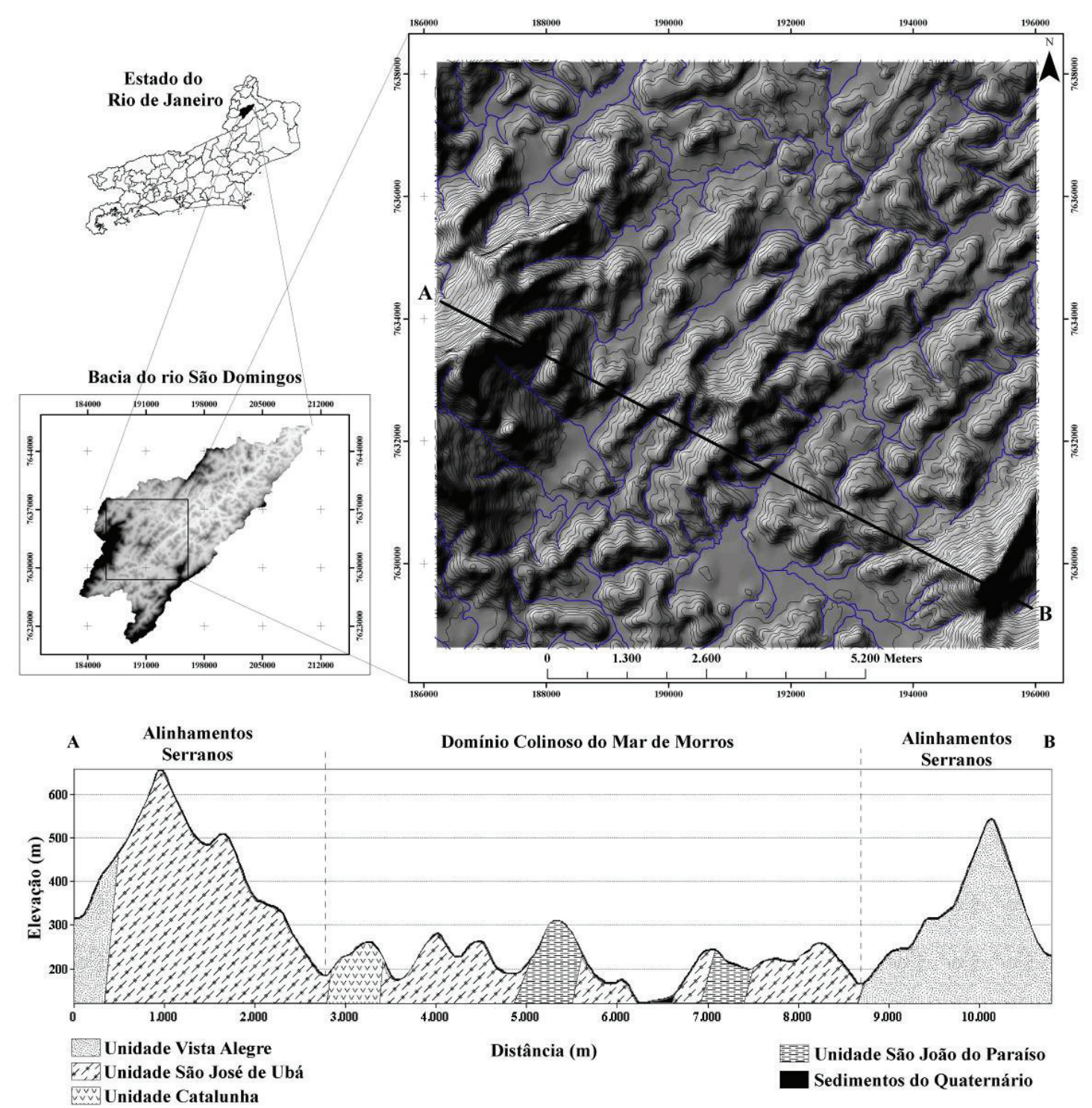

Um MDE foi obtido a partir da utilização dos dados relativos às curvas de nível, com eqüidistância vertical de $20 \mathrm{~m}$, hidrografia e pontos cotados contidos nas cartas topográficas do IBGE, na escala de 1:50.000, referentes às Folhas Miracema (SF-23-X-DIII-4) e São João do Paraíso (SF-24-G-I-3). O método escolhido para a elaboração do MDE foi baseado no ajustamento da superfície, utilizando o módulo TOPOGRID do software ARC/INFO.

Para caracterizar as relações solo-paisagem-material de origem na área estudada foram utilizados os seguintes atributos do terreno (Figura 2): elevação, declividade, aspecto, plano de curvatura e índice topográfico combinado (CTI, sigla em inglês), obtidos com o auxílio do software ArcGIS Desktop 10, e radiação solar obtida com a utilização da extensão Solar Analyst 1.0 (FU \& RICH, 1999; HEMI, 2000) no software ArcView GIS; além do mapa geológico da área.

$\mathrm{O}$ aspecto define a direção do fluxo de água e está relacionado diretamente com a evapotranspiração, insolação, teor de água no solo e consequentemente tem influência sobre os atributos do solo (MOORE et al., 1993; WILSON \& GALLANT, 2000).

O CTI é um atributo topográfico secundário, 
sendo definido como uma função da declividade e da área de contribuição por unidade de largura ortogonal à direção do fluxo, conforme a equação 1 :

$$
c t i=\mathbf{h}\left(\frac{A s}{\tan \beta}\right)
$$

onde, $\mathrm{A}_{\mathrm{s}}$, área de contribuição, é igual a (fluxo acumulado +1$) \times\left(\right.$ tamanho da célula do grid $\mathrm{em}^{2}$ ) e $\beta$ é a declividade expressa em radianos. Este índice foi desenvolvido para ser utilizado em estudo de topossequências em áreas declivosas.
A radiação solar também é um atributo secundário e foi calculada como uma função da latitude, declividade, aspecto, sombreamento topográfico, mudanças diárias e sazonais no ângulo solar e atenuação atmosférica (WILSON \& GALLANT, 2000; HEMI, 2000).

Figura 2. Atributos do Terreno da área estudada
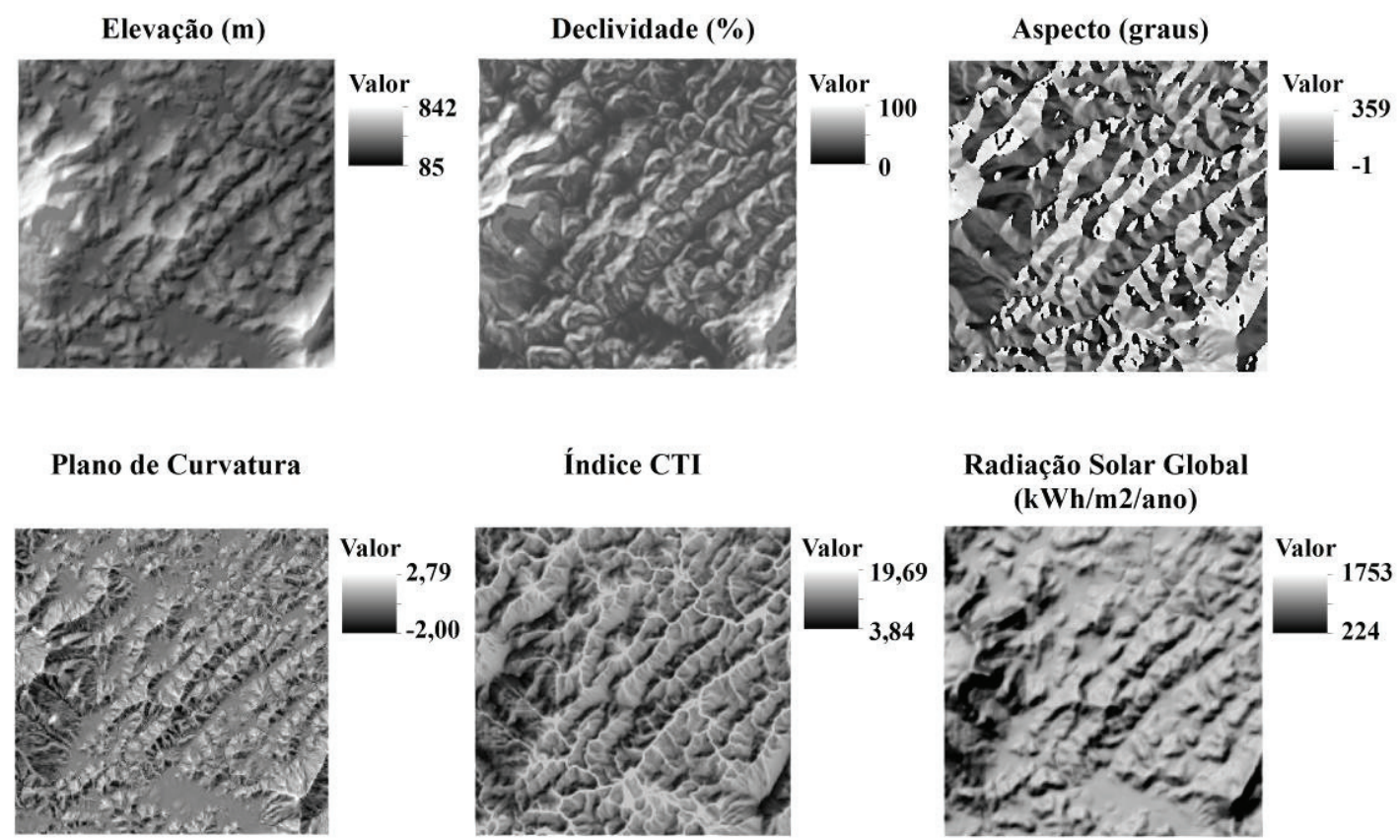

Índice CTI
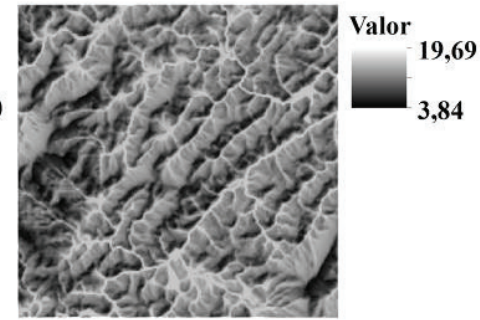

Radiação Solar Global (kWh/m2/ano)

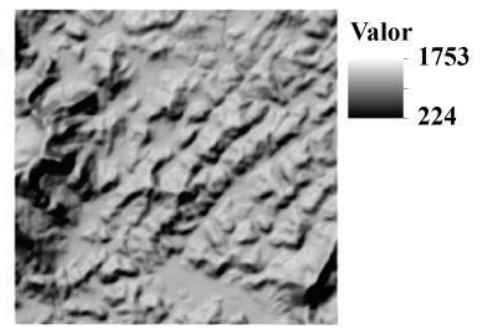

Org. dos autores.

A natureza das relações solo-paisagem-material de origem foram confirmadas utilizando-se 37 perfis de solo e 4 amostras extras, além de 83 observações sem coleta de amostras. As análises realizadas nestas amostras foram aquelas normalmente utilizadas nos levantamentos pedológicos, conforme métodos descritos em Embrapa (1997). Finalizando, os solos foram classificados de acordo com o Sistema Brasileiro de Classificação de Solos (SiBCS ) até o $4^{\circ}$ nível categórico (EMBRAPA, 2006).

\section{RESULTADOS E DISCUSSÃO}

As diferentes características da paisagem na área estudada, ditadas basicamente, pelos fatores de formação material de origem e relevo, condicionaram à formação de solos com características morfológicas, físicas e químicas distintas, conforme apresentado na Tabela 1. Nas Tabelas 3 e 4 são apresentadas as principais características físicas e químicas de perfis representativos destes solos. 
Relação entre atributos do terreno, material de origem e solos em uma área no noroeste do estado do Rio de Janeiro Cesar da Silva Chagas, Elpídio Inácio Fernandes Filho, Silvio Barge Bhering

Tabela 1. Unidades de solos identificadas na área estudada.

\begin{tabular}{|c|c|c|c|c|c|c|}
\hline Unidades & $\begin{array}{c}\text { Sistema de } \\
\text { Relevo }\end{array}$ & Litologia & Elevação & $\begin{array}{c}\text { Classe de Relevo } \\
\text { Dominante }\end{array}$ & Aspecto & Curvatura \\
\hline RLe & $\begin{array}{c}\text { Alinhamentos } \\
\text { Serranos }\end{array}$ & $\begin{array}{l}\text { Granulitos e } \\
\text { Migmatitos }\end{array}$ & $>300 \mathrm{~m}$ & Montanhoso e escarpado & Independe & Independe \\
\hline CXbe & $\begin{array}{c}\text { Alinhamentos } \\
\text { Serranos }\end{array}$ & $\begin{array}{l}\text { Granulitos e } \\
\text { Migmatitos }\end{array}$ & $>300 \mathrm{~m}$ & Forte ondulado & Independe & Independe \\
\hline PAe1 & Mar de Morros & Granulitos & $<300 \mathrm{~m}$ & Suave ondulado & Independe & Independe \\
\hline PAe2 & Mar de Morros & Migmatitos & $<300 \mathrm{~m}$ & Suave ondulado & Independe & Independe \\
\hline PVAd & $\begin{array}{c}\text { Alinhamentos } \\
\text { Serranos e Mar de Morros }\end{array}$ & Granulitos & $<300 \mathrm{~m}$ & $\begin{array}{l}\text { Forte ondulado e mon- } \\
\text { tanhoso }\end{array}$ & Sul & Convexa \\
\hline PVAe & $\begin{array}{c}\text { Alinhamentos } \\
\text { Serranos e Mar de Morros }\end{array}$ & Granulitos & $<300 \mathrm{~m}$ & Ondulado & Independe & Independe \\
\hline PVe1 & Mar de Morros & Migmatitos & $<300 \mathrm{~m}$ & Ondulado & Independe & Independe \\
\hline PVe2 & Mar de Morros & Migmatitos & $<300 \mathrm{~m}$ & $\begin{array}{l}\text { Forte ondulado e mon- } \\
\text { tanhoso }\end{array}$ & Norte & Convexa \\
\hline PVe3 & $\begin{array}{c}\text { Alinhamentos } \\
\text { Serranos e Mar de Morros }\end{array}$ & Migmatitos & $<300 \mathrm{~m}$ & $\begin{array}{l}\text { Forte ondulado e mon- } \\
\text { tanhoso }\end{array}$ & Sul & Convexa \\
\hline PVe4 & $\begin{array}{c}\text { Alinhamentos } \\
\text { Serranos e Mar de Morros }\end{array}$ & Granulitos & $<300 \mathrm{~m}$ & $\begin{array}{l}\text { Forte ondulado e mon- } \\
\text { tanhoso }\end{array}$ & Norte & Convexa \\
\hline PVe5 & $\begin{array}{c}\text { Alinhamentos } \\
\text { Serranos e Mar de Morros }\end{array}$ & $\begin{array}{l}\text { Granulitos e } \\
\text { Migmatitos }\end{array}$ & $<300 \mathrm{~m}$ & $\begin{array}{l}\text { Forte ondulado e mon- } \\
\text { tanhoso }\end{array}$ & Independe & Côncava \\
\hline GXve & $\begin{array}{c}\text { Sedimentos do Quater- } \\
\text { nário }\end{array}$ & $\begin{array}{c}\text { Sedimentos } \\
\text { do Quaternário }\end{array}$ & $<200 \mathrm{~m}$ & Plano & Independe & Plana \\
\hline
\end{tabular}

RLe - Neossolo Litólico Eutrófico típico + Afloramento de rocha; CXbe - Cambissolo Háplico Tb Eutrófico típico; PAe1 - Argissolo Amarelo Eutrófico típico; PAe2 - Argissolo Amarelo Eutrófico abrúptico; PVAd - Argissolo Vermelho-Amarelo Distrófico latossólico; PVAe - Argissolo Vermelho-Amarelo Eutrófico típico; PVe1 - Argissolo Vermelho Eutrófico abrúptico, relevo ondulado; PVe2

- Argissolo Vermelho Eutrófico abrúptico, relevo forte ondulado e montanhoso; PVe3 - Argissolo Vermelho Eutrófico abrúptico latossólico; PVe4 - Argissolo Vermelho Eutrófico típico ou nitossólico; PVe5 - Argissolo Vermelho Eutrófico saprolítico ou abrúptico saprolítico; GXve - Gleissolo Háplico Ta/Tb Eutrófico solódico ou típico.

Org. dos autores. 
A estatística descritiva dos atributos do terreno para cada unidade de solo identificada é apresentada na Tabela 2.

Tabela 2. Estatística descritiva dos atributos do terreno para as unidades de solos identificadas na área de estudo.

\begin{tabular}{|c|c|c|c|c|c|c|c|}
\hline Unidades & & $\begin{array}{l}\text { Elevação } \\
(\mathrm{m})\end{array}$ & $\begin{array}{l}\text { Declividade } \\
(\%)\end{array}$ & $\begin{array}{l}\text { Aspecto } \\
\text { (radianos) }\end{array}$ & $\begin{array}{l}\text { Plano de } \\
\text { Curvatura } \\
\end{array}$ & $\begin{array}{l}\text { Índice } \\
\text { CTI } \\
\end{array}$ & $\begin{array}{l}\text { Radiação solar } \\
\left(\mathbf{k W h} / \mathrm{m}^{2} / \mathbf{a n o}\right)\end{array}$ \\
\hline \multirow[t]{2}{*}{ RLe } & Média & 547 & 63 & 3,06 & 0,10 & 5,36 & 1024 \\
\hline & D.P. & 111 & 16 & 1,89 & 0,36 & 0,75 & 299 \\
\hline \multirow{2}{*}{ CXbe } & Média & 426 & 36 & 2,98 & $-0,07$ & 6,60 & 1368 \\
\hline & D.P. & 156 & 11 & 1,73 & 0,28 & 1,04 & 189 \\
\hline \multirow[t]{2}{*}{ PAe1 } & Média & 142 & 4 & 3,08 & 0,00 & 8,92 & 1633 \\
\hline & D.P. & 22 & 2 & 1,90 & 0,06 & 1,64 & 27 \\
\hline \multirow[t]{2}{*}{ PAe2 } & Média & 157 & 4 & 3,28 & 0,00 & 8,93 & 1626 \\
\hline & D.P. & 22 & 2 & 1,81 & 0,05 & 1,50 & 25 \\
\hline \multirow[t]{2}{*}{ PVAd } & Média & 207 & 32 & 2,89 & 0,15 & 5,74 & 1313 \\
\hline & D.P. & 63 & 9 & 0,85 & 0,22 & 0,73 & 142 \\
\hline \multirow[t]{2}{*}{ PVAe } & Média & 158 & 13 & 3,24 & 0,02 & 7,28 & 1592 \\
\hline & D.P. & 33 & 5 & 1,88 & 0,17 & 1,37 & 67 \\
\hline \multirow[t]{2}{*}{ PVe1 } & Média & 180 & 13 & 3,15 & 0,03 & 7,19 & 1580 \\
\hline & D.P. & 50 & 5 & 1,79 & 0,18 & 1,36 & 64 \\
\hline \multirow[t]{2}{*}{ PVe2 } & Média & 241 & 34 & 3,78 & 0,13 & 5,82 & 1522 \\
\hline & D.P. & 86 & 10 & 2,29 & 0,21 & 0,77 & 122 \\
\hline \multirow[t]{2}{*}{ PVe3 } & Média & 224 & 34 & 2,87 & 0,14 & 5,73 & 1281 \\
\hline & D.P. & 73 & 12 & 0,91 & 0,22 & 0,74 & 176 \\
\hline \multirow[t]{2}{*}{ PVe4 } & Média & 205 & 31 & 3,50 & 0,13 & 5,84 & 1543 \\
\hline & D.P. & 60 & 10 & 2,35 & 0,20 & 0,76 & 115 \\
\hline \multirow[t]{2}{*}{ PVe5 } & Média & 204 & 31 & 3,13 & $-0,21$ & 6,83 & 1415 \\
\hline & D.P. & 64 & 9 & 1,8 & 0,23 & 0,87 & 167 \\
\hline \multirow[t]{2}{*}{ GXve } & Média & 136 & 2 & 2,72 & 0,00 & 10,48 & 1643 \\
\hline & D.P. & 17 & 1 & 2,09 & 0,02 & 1,96 & 11 \\
\hline \multirow[t]{2}{*}{ Total } & Média & 214 & 24 & 3,16 & 0,03 & 6,80 & 1476 \\
\hline & D.P. & 114 & 16 & 1,84 & 0,23 & 1,66 & 200 \\
\hline
\end{tabular}

D.P. - Desvio Padrão. Org. dos autores.

Embora apresente grande variação altimétrica ( 85 a $842 \mathrm{~m}$ ), $85,5 \%$ da área apresentam altitudes inferiores a $300 \mathrm{~m}$ e estão associadas em sua maior parte ao Domínio Colinoso de Mar de Morros. Já os Alinhamentos Serranos do Noroeste Fluminense, ocupam 14,5\% da área (altitudes superiores a $300 \mathrm{~m}$ ) e apresentam direção preferencial NE-SW.

Nos Alinhamentos Serranos em áreas com elevação superior a $300 \mathrm{~m}$ (Figura 1) a declividade é o atributo do terreno que mais influencia a distribuição dos solos na paisagem condicionando a formação de solos com horizonte B incipiente ou até mesmo sem horizonte B diagnóstico. Assim, nas áreas muito íngremes com declividade média de 63\% (Tabela 2), independente da litologia (granulitos ou migmatitos), foram identificados Neossolos Litólicos Eutróficos típicos (RLe) associados com Afloramentos de Rocha (AR) e em declividades menos pronunciadas (média de 36\%) estão presentes Cambissolos Háplicos Tb Eutróficos típicos (CXbe). 
Relação entre atributos do terreno, material de origem e solos em uma área no noroeste do estado do Rio de Janeiro Cesar da Silva Chagas, Elpídio Inácio Fernandes Filho, Silvio Barge Bhering

Tabela 3. Características físicas dos perfis representativos

\begin{tabular}{|c|c|c|c|c|c|c|c|c|}
\hline \multirow{2}{*}{ Horizonte } & \multirow{2}{*}{$\begin{array}{l}\text { Profundidade } \\
\text { (cm) }\end{array}$} & \multirow{2}{*}{$\begin{array}{l}\text { Cor } \\
\text { úmida }\end{array}$} & \multicolumn{3}{|c|}{ Textura (g/kg) } & \multirow{2}{*}{$\begin{array}{l}\text { ADA } \\
\mathbf{g} / \mathbf{k g}\end{array}$} & \multirow{2}{*}{$\begin{array}{l}\text { GF } \\
\%\end{array}$} & \multirow{2}{*}{$\begin{array}{l}\text { Silte/ } \\
\text { argila }\end{array}$} \\
\hline & & & Areia & Silte & Argila & & & \\
\hline \multicolumn{9}{|c|}{ RLe - Neossolo Litólico Eutrófico típico } \\
\hline A & $0-24$ & 7,5 YR 3/1 & 443 & 339 & 218 & 146 & 33 & 1,56 \\
\hline \multicolumn{9}{|c|}{ CXbe - Cambissolo Háplico Tb Eutrófico típico } \\
\hline Ap & $0-26$ & $7,5 \mathrm{YR} 4 / 3$ & 569 & 167 & 264 & 243 & 8 & 0,63 \\
\hline Bi1 & $50-72$ & $7,5 \mathrm{YR} 4 / 6$ & 555 & 161 & 284 & 142 & 50 & 0,57 \\
\hline \multicolumn{9}{|c|}{ PAe1 - Argissolo Amarelo Eutrófico típico } \\
\hline Ap & $0-18$ & 10 YR $4 / 3$ & 340 & 179 & 481 & 262 & 46 & 0,37 \\
\hline $\mathrm{Bt} 2$ & $72-100$ & 7,5 YR5/6 & 234 & 121 & 645 & 0 & 100 & 0,19 \\
\hline \multicolumn{9}{|c|}{ PAe2 - Argissolo Amarelo Eutrófico abrúptico } \\
\hline Ap & $0-15$ & $10 Y R 4 / 3$ & 568 & 168 & 264 & 142 & 46 & 0,64 \\
\hline $\mathrm{Bt} 2$ & $62-91$ & $7,5 \mathrm{YR} 5 / 6$ & 250 & 116 & 634 & 0 & 100 & 0,18 \\
\hline \multicolumn{9}{|c|}{ PVAd - Argissolo Vermelho-Amarelo Distrófico latossólico } \\
\hline A1 & $0-8$ & 5 YR $3 / 3$ & 660 & 117 & 223 & 182 & 18 & 0,52 \\
\hline $\mathrm{Bt} 3$ & $97-120$ & 5 YR 5/6 & 274 & 54 & 672 & 0 & 100 & 0,08 \\
\hline Bw1 & $120-150$ & 5 YR $5 / 8$ & 308 & 62 & 630 & 0 & 100 & 0,10 \\
\hline \multicolumn{9}{|c|}{ PVAe - Argissolo Vermelho-Amarelo Eutrófico típico, relevo ondulado } \\
\hline Ap & $0-18$ & 5 YR $3 / 2$ & 481 & 174 & 345 & 325 & 6 & 0,50 \\
\hline Bt2 & $73-110$ & $3,5 \mathrm{YR} 4 / 8$ & 196 & 129 & 675 & 0 & 100 & 0,19 \\
\hline \multicolumn{9}{|c|}{ PVe1 - Argissolo Vermelho Eutrófico abrúptico, relevo ondulado } \\
\hline Ap & $0-18$ & $5 Y R 3 / 4$ & 559 & 177 & 264 & 203 & 23 & 0,67 \\
\hline $\mathrm{Bt} 2$ & $58-94$ & $2,5 \mathrm{YR} 4 / 7$ & 236 & 107 & 657 & 0 & 100 & 0,16 \\
\hline \multicolumn{9}{|c|}{ PVe2 - Argissolo Vermelho Eutrófico abrúptico, relevo forte ondulado ou montanhoso } \\
\hline Ap & $0-10$ & $7,5 \mathrm{YR} 3 / 2$ & 487 & 289 & 224 & 122 & 46 & 1,29 \\
\hline $\mathrm{Bt} 2$ & $53-118$ & $2,5 \mathrm{YR} 3 / 4$ & 214 & 127 & 659 & 556 & 16 & 0,19 \\
\hline \multicolumn{9}{|c|}{ PVe3 - Argissolo Vermelho Eutrófico abrúptico latossólico } \\
\hline Ap & $0-23$ & 5 YR $3 / 4$ & 522 & 154 & 324 & 284 & 12 & 0,48 \\
\hline Bt1 & $55-83$ & $2,5 \mathrm{YR} 4 / 5$ & 348 & 130 & 652 & 0 & 100 & 0,20 \\
\hline $\mathrm{Bt} 2$ & $83-150$ & $2,5 \mathrm{YR} 4 / 6$ & 273 & 239 & 488 & 0 & 100 & 0,49 \\
\hline $\mathrm{Bw}$ & $150-200$ & $3,5 \mathrm{YR} 4 / 7$ & 522 & 154 & 324 & 284 & 12 & 0,48 \\
\hline \multicolumn{9}{|c|}{ PVe4 - Argissolo Vermelho Eutrófico típico } \\
\hline A & $0-22$ & $5 \mathrm{YR} 4 / 3$ & 485 & 131 & 384 & 323 & 16 & 0,34 \\
\hline $\mathrm{Bt} 2$ & $67-108$ & $2,5 \mathrm{YR} 4 / 6$ & 207 & 64 & 729 & 0 & 100 & 0,09 \\
\hline \multicolumn{9}{|c|}{ PVe4- Argissolo Vermelho Eutrófico nitossólico } \\
\hline Ap & $0-20$ & $5 \mathrm{YR} 3 / 2$ & 363 & 166 & 471 & 369 & 22 & 0,35 \\
\hline $\mathrm{Bt} 2$ & $63-100$ & $2,5 \mathrm{YR} 4 / 6$ & 117 & 90 & 793 & 0 & 100 & 0,11 \\
\hline \multicolumn{9}{|c|}{ PVe5 - Argissolo Vermelho Eutrófico saprolítico } \\
\hline Ap & $0-17$ & $5 \mathrm{YR} 3 / 3$ & 280 & 270 & 450 & 246 & 45 & 0,60 \\
\hline $\mathrm{Bt}$ & $42-86$ & $2,5 \mathrm{YR} 3 / 6$ & 148 & 194 & 658 & 0 & 100 & 0,29 \\
\hline \multicolumn{9}{|c|}{ PVe5 - Argissolo Vermelho Eutrófico abrúptico saprolítico } \\
\hline Ap & $0-18$ & 5 YR $3 / 3$ & 556 & 200 & 244 & 163 & 33 & 0,82 \\
\hline $\mathrm{BA}$ & $18-35$ & 2,5 YR $3 / 3$ & 334 & 192 & 474 & 82 & 83 & 0,41 \\
\hline $\mathrm{Bt}$ & $35-65$ & $2,5 \mathrm{YR} 4 / 4$ & 383 & 184 & 433 & 41 & 91 & 0,42 \\
\hline \multicolumn{9}{|c|}{ GXve - Gleissolo Háplico Ta Eutrófico solódico } \\
\hline Ap & $0-22$ & 10YR 3/1 & 110 & 413 & 477 & 291 & 39 & 0,87 \\
\hline Cgn1 & $75-100$ & $2,5 Y$ 5/1 & 498 & 236 & 266 & 0 & 100 & 0,89 \\
\hline
\end{tabular}

ADA - argila dispersa em água; e GF - grau de floculação da argila.

Org. dos autores.

Soc. \& Nat., Uberlândia, 25 (1): 147-162, jan/abr/2013 


\begin{tabular}{|c|c|c|c|c|c|c|c|c|c|c|c|c|c|c|c|c|c|}
\hline \multirow[t]{2}{*}{ Horizonte } & \multicolumn{2}{|c|}{$\begin{array}{c}\mathrm{pH} \\
(1: 2,5)\end{array}$} & \multicolumn{6}{|c|}{$\begin{array}{c}\text { Complexo sortivo } \\
\left(\mathrm{cmol}_{\mathrm{c}} / \mathrm{kg}\right)\end{array}$} & \multirow{2}{*}{$\begin{array}{l}\mathrm{V} \\
\%\end{array}$} & \multirow{2}{*}{$\begin{array}{l}\mathrm{m} \\
\%\end{array}$} & & \multicolumn{4}{|c|}{$\begin{array}{c}\text { Ataque sulfúrico } \\
\mathrm{g} / \mathrm{kg}\end{array}$} & \multirow[t]{2}{*}{$\mathrm{Ki}$} & \multirow[t]{2}{*}{$\mathrm{Kr}$} \\
\hline & $\mathrm{H}_{2} \mathrm{O}$ & $\mathrm{KCl}$ & $\mathrm{Ca}^{2+}$ & $\mathbf{M g}^{2+}$ & $\mathbf{K}^{+}$ & $\mathrm{Na}^{+}$ & $\mathbf{S}$ & $\mathbf{T}$ & & & & $\mathrm{SiO}_{2}$ & $\mathrm{Al}_{2} \mathrm{O}_{3}$ & $\mathrm{Fe}_{2} \mathrm{O}_{3}$ & $\mathrm{TiO}_{2}$ & & \\
\hline \multicolumn{18}{|c|}{ RLe - Neossolo Litólico Eutrófico típico } \\
\hline A & 5,7 & 4,6 & 3,3 & 2,9 & 0,16 & 0,06 & 6,4 & 10,9 & 59 & 0 & 23,3 & - & - & - & - & - & - \\
\hline \multicolumn{18}{|c|}{ CXbe - Cambissolo Háplico Tb Eutrófico típico } \\
\hline Ap & 5,8 & 5,1 & 2,7 & 1,0 & 0,07 & 0,01 & 3,8 & 6,6 & 58 & 0 & 9,9 & - & - & - & - & - & - \\
\hline Bi1 & 5,4 & 5,0 & 1,9 & 0,5 & 0,01 & 0,01 & 2,4 & 4,7 & 51 & 0 & 4,7 & - & - & - & - & - & - \\
\hline \multicolumn{18}{|c|}{ PAe1 - Argissolo Amarelo Eutrófico típico } \\
\hline Ap & 5,9 & 5,3 & 3,6 & 1,5 & 0,72 & 0,02 & 5,8 & 9,3 & 63 & 0 & 9,8 & - & - & - & - & - & - \\
\hline Bt2 & 6,5 & 5,6 & 4,2 & 1,8 & 0,06 & 0,05 & 6,1 & 8,9 & 69 & 0 & 4,6 & 223 & 204 & 78 & 8,9 & 1,86 & 1,49 \\
\hline \multicolumn{18}{|c|}{ PAe2 - Argissolo Amarelo Eutrófico abrúptico } \\
\hline Ap & 6,1 & 5,2 & 3,3 & 1,5 & 0,72 & 0,02 & 5,5 & 8,5 & 65 & 0 & 9,8 & - & - & - & - & - & - \\
\hline Bt2 & 6,8 & 5,9 & 4,5 & 1,7 & 0,06 & 0,05 & 6,3 & 7,9 & 80 & 0 & 4,6 & 218 & 200 & 80 & 9 & 1,85 & 1,47 \\
\hline \multicolumn{18}{|c|}{ PVAd - Argissolo Vermelho-Amarelo Distrófico latossólico } \\
\hline A1 & 5,1 & 4,2 & 2,5 & 1,1 & 0,17 & 0,03 & 3,8 & 9,0 & 42 & 5 & 19,4 & - & - & - & - & - & - \\
\hline $\mathrm{Bt} 3$ & 5,0 & 4,1 & 0,3 & & 0,15 & 0,05 & 0,5 & 3,6 & 14 & 62 & 2,8 & 230 & 206 & 92 & 10,9 & 1,90 & 1,48 \\
\hline Bw1 & 5,0 & 4,1 & 0,3 & & 0,13 & 0,05 & 0,5 & 3,6 & 14 & 62 & 2,4 & 207 & 195 & 85 & 10,9 & 1,80 & 1,41 \\
\hline \multicolumn{18}{|c|}{ PVAe - Argissolo Vermelho-Amarelo Eutrófico típico, relevo ondulado } \\
\hline Ap & 5,6 & 4,7 & 1,9 & 1,0 & 0,31 & 0,02 & 3,2 & 6,0 & 53 & 6 & 9,9 & - & - & - & - & - & - \\
\hline Bt2 & 5,3 & 5,2 & 0,6 & 1,9 & 0,02 & 0,04 & 2,6 & 4,4 & 59 & 0 & 3,4 & 231 & 224 & 103 & 9,5 & 1,75 & 1,35 \\
\hline \multicolumn{18}{|c|}{ PVe1 - Argissolo Vermelho Eutrófico abrúptico, relevo ondulado } \\
\hline Ap & 5,8 & 4,8 & 3,8 & 1,4 & 0,27 & 0,02 & 5,5 & 7,0 & 79 & 0 & 11,8 & - & - & - & - & - & - \\
\hline Bt2 & 6,3 & 5,5 & 4,2 & 2,2 & 0,06 & 0,02 & 6,5 & 7,0 & 93 & 0 & 5,8 & 209 & 210 & 104 & 11,4 & 1,69 & 1,28 \\
\hline \multicolumn{18}{|c|}{ PVe2 - Argissolo Vermelho Eutrófico abrúptico, relevo forte ondulado ou montanhoso } \\
\hline Ap & 6,6 & 5,6 & 5,6 & 1,8 & 1,58 & 0,03 & 9,0 & 11,5 & 78 & 0 & 16,0 & - & - & - & - & - & - \\
\hline $\mathrm{Bt} 2$ & 7,0 & 5,8 & 10,3 & 1,4 & 0,09 & 0,05 & 11,8 & 11,8 & 100 & 0 & 5,9 & 202 & 203 & 85 & 9,5 & 1,69 & 1,33 \\
\hline PVe3 - Arg & solo Ve & rmelho & Eutrófi & o abrú & tico lat & ssólico & & & & & & & & & & & \\
\hline Ap & 6,7 & 6,0 & 2,8 & 1,2 & 0,53 & 0,01 & 4,5 & 6,0 & 75 & 0 & 12,5 & - & - & - & - & - & - \\
\hline Bt1 & 6,5 & 5,7 & 2,2 & 0,4 & 0,19 & 0,01 & 2,8 & 4,1 & 68 & 0 & 3,7 & 200 & 212 & 103 & 10,0 & 1,60 & 1,22 \\
\hline Bt2 & 6,9 & 6,1 & 1,9 & 0,6 & 0,07 & 0,01 & 2,6 & 3,6 & 72 & 0 & 2,3 & 216 & 228 & 105 & 8,7 & 1,61 & 1,24 \\
\hline $\mathrm{Bw}$ & 6,7 & 6,3 & 1,2 & 0,8 & 0,03 & 0,01 & 2,0 & 2,8 & 71 & 0 & 12,5 & 203 & 214 & 105 & 8,9 & 1,61 & 1,23 \\
\hline PVe4 - Arg & solo Ve & rmelho & Eutrófi & o típic & & & & & & & & & & & & & \\
\hline Ap & 5,2 & 4,6 & 2,5 & 1,1 & 0,09 & 0,01 & 3,7 & 6,2 & 60 & 3 & 8,6 & - & - & - & - & - & - \\
\hline Bt2 & 5,4 & 4,5 & 1,6 & 1,4 & 0,03 & 0,04 & 3,1 & 5,6 & 55 & 3 & 3,2 & 166 & 182 & 79 & 13,2 & 1,55 & 1,21 \\
\hline PVe4 -Argi & solo Ve & melho & Eutrófi & o nitos & blico & & & & & & & & & & & & \\
\hline Ap & 5,8 & 5,2 & 3,4 & 1,8 & 0,45 & 0,01 & 5,7 & 8,4 & 68 & 0 & 15,5 & - & - & - & - & - & - \\
\hline $\mathrm{Bt} 2$ & 6,2 & 5,6 & 1,6 & 2,2 & 0,14 & 0,02 & 4,0 & 5,7 & 70 & 0 & 4,7 & 259 & 254 & 108 & 12,0 & 1,73 & 1,36 \\
\hline PVe5 - Arg & solo Ve & rmelho & Eutrófi & o sapr & ítico & & & & & & & & & & & & \\
\hline Ap & 6,1 & 5,4 & 3,7 & 1,2 & 0,34 & 0,02 & 5,3 & 7,7 & 69 & 0 & 18,1 & - & - & - & - & - & - \\
\hline $\mathrm{Bt}$ & 6,2 & 5,5 & 3,4 & 1,7 & 0,04 & 0,06 & 5,2 & 7,6 & 68 & 0 & 5,9 & 226 & 218 & 89 & 9,2 & 1,76 & 1,40 \\
\hline PVe5 - Arg & solo Ve & rmelho & Eutrófi & o abrú & ico sap & olítico & & & & & & & & & & & \\
\hline Ap & 5,8 & 5,1 & 4,5 & 2,0 & 0,17 & 0,02 & 6,7 & 8,8 & 76 & 0 & 13,2 & 94 & 83 & 58 & 11,1 & 1,93 & 1,33 \\
\hline $\mathrm{BA}$ & 6,9 & 5,8 & 8,7 & 1,4 & 0,45 & 0,04 & 10,6 & 11,4 & 93 & 0 & 6,9 & 177 & 177 & 82 & 6,2 & 1,70 & 1,31 \\
\hline $\mathrm{Bt}$ & 7,1 & 5,8 & 8,5 & 1,1 & 0,14 & 0,05 & 9,8 & 9,8 & 100 & 0 & 4,4 & 179 & 177 & 82 & 6,2 & 1,72 & 1,33 \\
\hline GXve - G & ssolo $\mathrm{H}$ & áplico & a Eutrc & fico sol & dico & & & & & & & & & & & & \\
\hline $\mathrm{Ap}$ & 5,4 & 4,6 & 7,9 & 4,6 & 0,32 & 0,27 & 13,1 & 17,6 & 74 & 0 & 15,8 & - & - & - & - & - & - \\
\hline Cgn1 & 6,1 & 4,8 & 3,0 & 4,1 & 0,07 & 0,83 & 8,0 & 9,3 & 86 & 0 & 2,5 & - & - & - & - & - & - \\
\hline
\end{tabular}

$\mathrm{S}$ - soma de bases; $\mathrm{T}$ - capacidade de troca de cátions a pH 7,0; V - saturação por bases; $\mathrm{m}$ - saturação por alumínio e C - carbono orgânico.

Org. dos autores. 
Conforme destacado por Hall \& Olson (1991) e Grossman (1983), o elevado gradiente do relevo acelera o processo erosivo provocando uma constante remoção dos horizontes superficiais do solo (morfogênese $>$ pedogênese $=$ processo de rejuvenescimento). Este processo de rejuvenescimento é tanto maior quanto maior é a declividade. Deste modo, os solos são pouco profundos ou rasos $(<100 \mathrm{~cm})$ e nos casos mais drásticos de remoção do solo as rochas foram expostas (AR).

As unidades RLe e CXbe (Tabelas 3 e 4) apresentam como principais características a textura média ou média/argilosa e a elevada saturação por bases, com valores médios no horizonte A superiores a $59 \%$ e de $73 \%$ no horizonte B. Os Cambissolos Háplicos, independente da litologia, exibem mais frequentemente argila de atividade baixa (CTC $<27$ $\mathrm{cmol}_{\mathrm{c}} / \mathrm{kg}$ ), com valores médios inferiores a $10 \mathrm{cmol}_{\mathrm{c}} /$ $\mathrm{kg}$ (Tabela 4).

$\mathrm{Na}$ área do Domínio do Mar de Morros (elevação $<300 \mathrm{~m}$ ), e em menor proporção nos Alinhamentos Serranos (Figura 1), os atributos primários declividade, aspecto e plano de curvatura, auxiliados pelos atributos secundários índice CTI e radiação solar, atuam de forma marcante na diferenciação dos solos.

A declividade tem sido considerada um dos mais importantes atributos topográficos primários que controlam os processos pedogenéticos, pois afeta diretamente a velocidade do fluxo superficial e subsuperficial de água e consequentemente o teor de água no solo, o potencial de erosão/deposição, e muitos outros processos importantes (GALLANT \& WILSON, 2000). Sendo assim, as unidades PAe1, PAe2, PVe1, PVAe e GXve (Tabela 1) são diretamente influenciadas por este atributo. As unidades PAe1 e PAe2 apresentam declividade média de 4\% (suave ondulado), nas unidades PVe1 e PVAe os valores são de $13 \%$ (ondulado) e a unidade GXve apresenta as menores declividades médias, apenas $2 \%$ (plano).

Corroborando a influência da declividade verifica-se que o índice CTI para estas unidades é mais elevado do que para as demais, com valores médios de 8,92 (PAe1), 8,93 (PAe2), 7,19 (PVe1), 7,28 (PVAe) e 10,48 (GXve), sendo que os valores para toda a área variam de 3,8 a 19,7, com média de 6,8. Aproxima- damente $95 \%$ das células da área apresentam valores inferiores a 10,0 (MOORE et al., 1993), sendo que os valores elevados estão relacionados com as áreas planas de baixada, que favorecem o acúmulo de água no solo, ou com áreas côncavas nas partes mais elevadas e declivosas da área, onde o fluxo superficial de água é convergente (GALLANT \& WILSON, 2000). Nestas condições, a curvatura do terreno, o aspecto e a radiação solar têm pouca influência sobre a pedogênese destes solos. A curvatura do terreno, em função do baixo gradiente de relevo tem atuação pouco marcante no processo de rejuvenescimento dos solos não se expressando com a mesma magnitude com que se expressa nas áreas mais acidentadas, o que é corroborado pelos valores muito baixos para o plano de curvatura, sendo de 0 para as unidades PAe1, PAe2 e GXve, de 0,03 para a unidade PVe1 e de 0,02 para a unidade PVAe, configurando áreas planas ou suavemente onduladas.

O aspecto também tem sua importância reduzida nestas áreas. Segundo Mitasova \& Hofierka (1993), esta se torna menos significativa quando a declividade é pequena, pois células com declividades muito baixas são consideradas como tendo orientação indefinida, exercendo pouca ou quase nenhuma influência na diferenciação dos solos. Os valores médios para o aspecto nestas unidades são muito semelhantes variando de 2,72 radianos na unidade GXve a 3,28 radianos na unidade PAe2 (Tabela 2).

Em função das baixas declividades e da pouca influência do aspecto, a radiação solar potencial, por conseguinte, também não teve influência na diferenciação destes solos (PAe1, PAe2, GXve, PVe1 e PVAe) o que é comprovado pelos valores médios da radiação solar global (Tabela 2) muito semelhantes entre estas unidades, sendo de 1633,1626 e $1643 \mathrm{kWh} / \mathrm{m}^{2} /$ ano nas unidades PAe1, PAe2 e GXve, respectivamente e ligeiramente inferiores nas unidades PVe1 e PVAe (1580 e $1592 \mathrm{kWh} / \mathrm{m}^{2} /$ ano, respectivamente).

Os solos das unidades PAe1 e PAe2 por ocorrerem em áreas de terço inferior constituídas por pequenas elevações isoladas de baixíssima amplitude de relevo apresentam coloração do horizonte B amarelada (> 5YR). Estas duas unidades diferenciam-se apenas pela presença de mudança textural abrupta (caráter abrúptico) na unidade PAe2, derivada dos migmatitos 
heterogêneos e ausência na unidade PAe1, derivada dos granulitos noríticos. De modo geral, apresentam saturação por bases elevada (> 60\%) e baixos valores de $\mathrm{Fe}_{2} \mathrm{O}_{3}$ do ataque sulfúrico $(<80 \mathrm{~g} / \mathrm{kg})$, sendo, portanto, hipoférricos.

As unidades PVe1 e PVAe ocupam porções expressivas da área, em encostas isoladas de baixa amplitude ou em posição de terço inferior ligeiramente acima das unidades PAe1 e PAe2. Estas unidades são formadas por Argissolos Vermelhos e Argissolos Vermelho-Amarelos, cuja principal diferença é a cor que varia de 5YR a 3,5YR nos Vermelho-Amarelos e nos Vermelhos é 2,5YR. Tal caraterística é normal nesta unidade e provavelmente está relacionada com diferenças no regime de umidade do solo causado pela variabilidade no material de origem.

A textura nestes solos é média/muito argilosa, média/argilosa ou argilosa/muito argilosa, sendo que a mudança textural abrupta só é identificada nos solos da unidade PVe1, derivados dos migmatitos heterogêneos e por essa razão foram classificados como abrúpticos no $4^{\circ}$ nível categórico do SiBCS (Embrapa, 2006), enquanto os da unidade PVAe são típicos. Os valores da relação silte/argila inferiores a 0,3 em todos os perfis analisados é uma tendência geral nos Argissolos da área estudada, independente do tipo de material de origem dos solos. Todos apresentam elevada saturação por bases, alcançando $100 \%$ em alguns perfis e baixa CTC. Os teores de $\mathrm{Fe}_{2} \mathrm{O}_{3}$ do ataque sulfúrico no horizonte B superiores a $80 \mathrm{~g} / \mathrm{kg}$ (mesoférricos) são uma herança do material de origem. Já os valores de $\mathrm{Ki}$ inferiores a 2,0 acompanham a tendência verificada nos demais Argissolos (Tabela 4).

Os Sedimentos Aluvionares do Quaternário são bastante expressivos na área. Tais sedimentos formados em condições de inundação são compostos por areias e argilas e depósitos de várzea (DRM, 1980). Esses fundos de vales estão delimitados pelo relevo colinoso, característico da depressão interplanáltica do norte-noroeste fluminense e foram originados a partir do entulhamento/deposição de sedimentos aluviais provenientes da bacia de drenagem do rio São Domingos (DANTAS, 2000), o que, ainda, é verificado atualmente.

Os solos relacionados com estes sedimentos são dominantemente os Gleissolos Háplicos Ta ou Tb
Eutrófico solódico ou típico. Estes apresentam matiz variando de $10 \mathrm{YR}$ a $2,5 \mathrm{Y}$, indicando um processo pouco intenso de gleização, ainda que apresentem lençol freático elevado. $\mathrm{O}$ valor ao redor de 5 e o croma de 1, em todos os perfis, indicam uma desferrificação expressiva (CAMPOS et al., 2003). Todos os perfis analisados apresentam mosqueados comuns e abundantes, sugerindo uma boa mobilidade de Fe no sistema. A textura é bastante variada (média, média/argilosa, média/argilosa/muito argilosa, argilosa/ muito argilosa/média e argilosa) e comum nos solos de várzea, refletindo a natureza do material depositado e o tipo de deposição desses sedimentos.

A saturação por bases nos Gleissolos é sempre elevada, com valores entre 53 e $100 \%$ e a atividade da argila é alta, com valores superiores a $30 \mathrm{cmol}_{\mathrm{c}} / \mathrm{kg}$ (Tabela 4), podendo esta ser atribuída a uma massiva neoformação de minerais de argila 2:1 a partir de compostos solúveis liberados pelo intemperismo geoquímico, provenientes dos solos da parte superior das encostas e acumulados nestas áreas (DUCHAUFOUR, 1998). Alguns perfis apresentam caráter solódico em profundidade (saturação por sódio entre 6 e 15\%), devido ao acúmulo do $\mathrm{Na}^{+}$liberado, principalmente pelo intemperismo dos plagioclásios, comuns nos granulitos e migmatitos. Além do mais, este é um ambiente conservador, já que os córregos têm uma vazão muito limitada, o que dificulta a remoção deste cátion para fora do sistema.

No Domínio de Mar de Morros (elevação < $300 \mathrm{~m}$ ), e em menor proporção nos Alinhamentos Serranos (Figura 1), em áreas com declividades superiores a $20 \%$, a curvatura do terreno, o aspecto e a radiação solar passam a ter papel fundamental na diferenciação dos solos. Assim, foram identificados nestas áreas as unidades PVAd, PVe2, PVe3, PVe4 e PVe5 (Tabela 1).

A influência da curvatura do terreno sobre as propriedades dos solos tem sido relacionada, principalmente, ao controle que as formas côncava e convexa exercem sobre a distribuição de água e materiais solúveis das partes mais elevadas para as mais baixas. O plano de curvatura (taxa de variação do aspecto ao longo da curva de nível) mede a propensão de a água convergir ou divergir à medida que atravessa o terreno (GALLANT \& WILSON, 2000). Com relação a este atributo $41,38 \%$ das encostas da área são convexas, 
$29,43 \%$ são côncavas e aproximadamente $29,19 \%$ da área constituem áreas planas.

De acordo com Hall \& Olson (1991) e Phillips et al. (2001), a curvatura do terreno modifica a força erosiva do fluxo superficial de água e influencia o caminho do movimento desta através do solo. Desta forma, os solos tendem a se tornarem saturados e a infiltração a ocorrer nas partes inferiores da encosta e nas posições elevadas onde a encosta é côncava (fluxo superficial de água convergente). Por sua vez, nas encostas convexas, onde o fluxo superficial de água é divergente (GALLANT \& WILSON, 2000), a força erosiva da água é menor do que nas encostas côncavas, tornando a remoção do solo pela erosão menos expressiva.

Verificou-se uma estreita relação entre o plano de curvatura e a espessura dos solos. Como regra geral, os solos mais profundos e mais evoluídos ocupam encostas convexas, enquanto os mais rasos (saprolíticos) e menos evoluídos tendem a ocorrer em encostas côncavas. As unidades PVAd, PVe2, PVe3 e PVe4 ocupam dominantemente encostas convexas e apresentam valores médios para o plano de curvatura de 0,15 (PVAd), 0,13 (PVe2 e PVe4) e 0,14 (PVe3), sendo que os valores na área variam de $-2,0$ a 2,8, com valores negativos representando encostas côncavas e os valores positivos encostas convexas.

Resultados divergentes foram obtidos por Gessler et al. (2000), que em condições de clima temperado verificaram que áreas côncavas, dominadas por processos de acumulação ou ganho de água e sedimentos, apresentavam solos mais evoluídos, enquanto nas áreas convexas a dominância dos processos de perda de água e sedimentos levou à formação de solos sem horizontes diagnósticos significativos ou horizontes fracamente desenvolvidos.

Por outro lado, a unidade PVe5 ocupa exclusivamente as encostas côncavas, com média de $-0,21$ para o plano de curvatura. Em função disso, os solos desta unidade (Argissolo Vermelho Eutrófico saprolítico ou abrúptico saprolítico) apresentam espessura dos perfis inferiores a $100 \mathrm{~cm}$ (pouco profundos ou rasos), sendo este o principal diferencial para com os solos que ocorrem nas encostas convexas. De modo geral, as características físicas e químicas são semelhantes as dos demais Argissolos (Tabelas 3 e 4).
Contrastando com as condições descritas anteriormente, nas encostas convexas os solos são mais bem desenvolvidos, apresentando profundidade superior a $150 \mathrm{~cm}$. Nestas encostas, a radiação solar, como uma função da declividade e do aspecto, tem um papel importante na diferenciação dos solos, pois afeta diretamente o regime de temperatura do ar e do solo, a evapotranspiração e a umidade do solo. Consequentemente, importantes características dos solos são afetadas, entre elas, a cor, a saturação de bases e a presença de horizonte B latossólico em profundidade. Vários estudos têm mostrado indiretamente através da análise do aspecto esta influência sobre a distribuição dos solos na paisagem (LOTSPEICH \& SMITH, 1953; FINNEY et al., 1962; BIRKELAND, 1984; THOMAS et al., 1999; ZHU et al., 2001).

Os dados sobre a radiação solar mostram que existe uma considerável variação da insolação na área. As encostas voltadas para norte apresentam valores médios mais elevados $\left(1533 \mathrm{kWh} / \mathrm{m}^{2} / \mathrm{ano}\right)$ do que aquelas voltadas para sul $\left(1319 \mathrm{kWh} / \mathrm{m}^{2} / \mathrm{ano}\right)$. A menor radiação solar incidente nas encostas voltadas para sul se deve também ao maior efeito do sombreamento topográfico, em partes do dia, verificado nestas encostas. As unidades que ocupam as encostas voltadas para norte $\mathrm{PVe} 2$ (migmatitos) e $\mathrm{PVe} 4$ (granulitos) apresentam valores médios (1522 e $1543 \mathrm{kWh} /$ $\mathrm{m}^{2} /$ ano, respectivamente) superiores aos das unidades PVAd (granulitos) e PVe3 (migmatitos) que ocupam as encostas voltadas para sul.

Nas unidades PVe2 (Argissolo Vermelho Eutrófico abrúptico) e PVe4 (Argissolo Vermelho Eutrófico típico ou nitossólico) os solos apresentam coloração avermelhada (matiz 2,5YR ou mais verme1ho), condicionada pela presença de hematita, que por sua vez é governada por vários fatores, entre eles: teor e taxa de liberação de Fe da rocha, temperatura do solo, teor de matéria orgânica, $\mathrm{pH}, \mathrm{Al}^{3+}$, sílica e umidade do solo (Schwertmann \& Kämpf, 1985). A maior radiação solar incidente sobre as encostas voltadas para norte tornam estas encostas relativamente mais quentes e mais secas (maior evapotranspiração) do que aquelas voltadas para sul, o que parece favorecer a formação de hematita em relação à goethita, devido ao maior potencial redox e temperatura do solo mais elevada, a qual acelera a mineralização da matéria orgânica, ori- 
ginando maior disponibilidade de $\mathrm{Fe}^{3+}$ e favorecendo a desidratação da ferrihidrita à hematita (KÄMPF \& SCHWERTMANN, 1983).

Estes apresentam textura média/argilosa, média/muito argilosa, argilosa ou argilosa/muito argilosa, sendo este atributo controlado basicamente pelo material de origem (Tabela 3). Todos exibem gradiente textural mais ou menos elevado, com os Argissolos da unidade PVe2 apresentando mudança textural abrupta (caráter abrúptico), que vem a ser a principal diferença encontrada entre os solos destas unidades (PVe2 - abrúptico e PVe4 - típico ou nitossólico) e que é controlada exclusivamente pelo material de origem dos solos. Todos os perfis destas unidades possuem elevados valores de saturação por bases e baixos valores de CTC (argila de atividade baixa).

Os solos da unidade PVAd (granulitos), que ocupam as encostas voltadas para sul, apresentam valores médios da radiação solar incidente de 1313 $\mathrm{kWh} / \mathrm{m}^{2} /$ ano e são vermelho-amarelados. Segundo Tardy \& Nahon (1985), o principal agente controlador do equilíbrio entre goethita e hematita no solo é a atividade da água. Quando a atividade da água é pequena, a hematita torna-se o óxido de ferro predominante, enquanto que o aumento da atividade da água propicia o aumento na participação da goethita. Desta maneira, nos solos derivados dos granulitos das encostas relativamente mais frias e úmidas (sul) o microclima diferenciado favorece a transformação de hematita em goethita (xantização), consequentemente, os solos são mais amarelados do que aqueles das encostas mais quentes e secas (norte).

Por outro lado, os solos da unidade PVe3 (migmatitos), embora também localizados nas encostas sul, com valores médios de radiação solar de $1281 \mathrm{kWh} / \mathrm{m}^{2} /$ ano, apresentam cor avermelhada $(\geq$ 2,5YR). Neste caso, como a cor avermelhada do solo é dada pela hematita e a sua presença é governada entre outros fatores pelo teor e taxa de liberação de Fe da rocha (Schwertmann \& Kämpf, 1985), provavelmente, a maior riqueza em minerais ricos em ferro como: granada, biotita, cordierita, piroxênios e anfibólios (hornblenda) presentes nos migmatitos e, a facilidade de intemperismo destes minerais resulte em uma taxa de liberação de ferro mais elevada do que aquela verificada nos granulitos, favorecendo, desta maneira, a formação de hematita, mesmo em condições de umidade relativamente mais elevada, como se verifica nas encostas voltadas para sul.

Outra característica que parece ter sido afetada pelo aspecto e em consequência pela radiação solar é a saturação por bases (BIRKELAND, 1984) nos solos derivados dos granulitos. Os solos da unidade PVAd são distróficos, com saturação por bases variando entre 14 e 47\%, com média de 33\%. Embora apresentem valores medianos de saturação por bases, estes são significativamente inferiores àqueles da unidade PVe4 (Tabela 4). Estes resultados podem ser atribuídos ao microclima relativamente mais úmido, que favorece o processo de intemperismo-lixiviação, levando a um empobrecimento relativo de bases e, consequente, enriquecimento de alumínio trocável.

A influência do aspecto e da radiação solar incidente sobre a pedogênese também foi identificada nos Argissolos Vermelho-Amarelos Distróficos latossólicos (PVAd), que são mais intemperizados, mais profundos, com menor relação silte/argila e menor saturação por bases do que os Argissolos Vermelhos Eutróficos típicos (PVe4) (Tabelas 3 e 4). Corroborando essa maior evolução pedogenética os solos da unidade PVAd apresentam horizonte B latossólico em profundidade abaixo do horizonte $\mathrm{B}$ textural o que não foi detectado nos solos da unidade PVe4.

A saturação por bases não variou em função do aspecto e da radiação solar incidente nos solos derivados dos migmatitos. Assim, os solos da unidade PVe3 também são eutróficos, com valores entre 52 e $100 \%$ (Tabela 4). Por outro lado, as condições relativamente mais úmidas foram suficientes para favorecer o desenvolvimento de um horizonte $\mathrm{B}$ latossólico abaixo do horizonte diagnóstico B textural, dentro de 200 $\mathrm{cm}$ de profundidade. A morfologia determinada pela estrutura fraca a moderada em blocos subangulares que se desfazem em forte muito pequena granular e pela ausência de cerosidade, é a única diferença entre os horizontes $\mathrm{Bt}$ e $\mathrm{Bw}$ destes solos.

Finalizando, a utilização de técnicas de geoprocessamento e análise digital do terreno auxiliaram na identificação das interações que ocorrem entre os diferentes fatores de formação dos solos, levando à formação de combinações que permitiram explicar as relações existentes entre as litologias, os atributos do 
terreno e os solos, que foram posteriormente empregadas no mapeamento digital de solos da área utilizando redes neurais artificiais.

\section{CONCLUSÕES}

A forte influência dos atributos do terreno é bem conhecida na literatura e foi confirmada neste estudo, com os atributos influenciando diferentemente a distribuição dos solos na paisagem. O material de origem teve influência marcante na ausência ou presença de mudança textural abrupta nos solos da área, sendo esta a principal diferença entre os Argissolos derivados de granulitos (sem mudança textural abrupta) e os Argissolos derivados dos migmatitos heterogêneos (com mudança textural abrupta).

A curvatura do terreno, que controla o fluxo superficial de água no solo, é o principal fator que determina a profundidade do solo entre as encostas côncavas e convexas, com os solos menos profundos ocupando as encostas côncavas e os mais profundos as encostas convexas.

Variações microclimáticas condicionadas pelo aspecto e radiação solar incidente foram determinantes para a diferenciação dos solos nas encostas convexas, tanto nos solos derivados de granulitos quanto nos derivados dos migmatitos heterogêneos, sendo a cor do solo, a saturação por bases e a presença ou ausência de horizonte B latossólico em profundidade, as principais características afetadas.

Por sua vez, as áreas de baixa amplitude de relevo próximo das várzeas não sofreram influência da curvatura, do aspecto e da radiação solar, sendo os solos condicionados apenas pela declividade e posição na paisagem.

\section{REFERÊNCIAS}

BIRKELAND, P. W. Soils and geomorphology. New York: Oxford University Press, 1984. 430p.

CAMPOS. C. E. B.; LANI, J. L.; RESENDE, M. \& REZENDE, S. B. Indicadores de campo para solos hidromórficos na região de Viçosa (MG). Revista Brasileira de Ciência do Solo, v.27, p.1057-1066, 2003.
CHAPLOT, V.; WALTER, C. \& CURMI, P. Modeling soil spatial distribution: sensitivity to DEM resolutions and pedological data availability. In: WORLD CONGRESS OF SOIL SCIENCE, 16., 1998, Montpellier, France. Proceedings ... Montpellier: IUSS, 1998.

DANTAS, M. E. Geomorfologia do Estado do Rio de Janeiro. Brasília: CPRM, 2000.

DEPARTAMENTO DE RECURSOS MINERAIS DRM-RJ. Projeto Carta Geológica do Estado do Rio de Janeiro na Escala 1:50.000. Folhas: Miracema e São João do Paraíso. 1980.

DIXON, T. H. SAR Interferometry and Surface Change Detection. University of Miami, Rosenstiel School of Marine and Atmospheric Sciences, RASMAS TR 95-003, 1995.

DUCHAUFOUR, P. Handbook of pedology: soils, vegetation and environment. Brookfield: Balkema Publishers, 1998. 264p.

EMBRAPA. Centro Nacional de Pesquisa de Solos. Manual de métodos de análise do solo. 2. ed. rev. e atual. Rio de Janeiro: EMBRAPA-CNPS, 1997. 212p. (EMBRAPA-CNPS. Documentos, 1).

EMBRAPA. Centro Nacional de Pesquisa de Solos. Sistema Brasileiro de Classificação de Solos. Brasília: Embrapa Produção de Informação; Rio de Janeiro: Embrapa Solos, 2006. 412 p.

FINNEY, H. R.; HOLOWAYCHUK, N. \& HEDDLESON, M. R. The influence of microclimate on the morphology of certain soils of the Allegheny plateau of Ohio. Soil Science Society of American Proceedings, v.26, p.287-292, 1962.

FLORINSKY, I. \& KURYAKOVA, G. Determination of grid size for digital terrain models in soil investigations. In: World Congress of Soil Science, 16., 1998, Montpellier, France. Proceedings... Montpellier: IUSS, 1998. 
FU, P. \& RICH, P. M. Design and Implementation of the Solar Analyst: An ArcView Extension for Modeling Solar Radiation at Landscape Scales. ESRI International User Conference Proceedings. San Diego, California: ESRI, July 26-30, 1999.

GALLANT, J. C. \& WILSON, J. P. Primary topographic attributes. In: WILSON, J. P. \& GALLANT, J. C. (Eds.). Terrain Analysis: Principles and applications. New York: John Wiley \& Sons, 2000. p.51-85.

GARBRECHT, J.; OGDEN, F. L.; DeBARRY, P. A. \& MAIDMENT, P. A. GIS and distributed watershed models. 1: data coverages and sources. Journal of Hydrologic Engineering, v.6, p.506-514, 2001.

GESSLER, P. E. et al. Modeling soil-landscape and ecosystem properties using terrain attributes. Soil Science Society of American Journal, v.64, p.20462056, 2000.

GROSSMAN, R. B. Entisols. In: WILDING, L. P.; SMECK, N. E. \& HALL, G. F. (Eds.). Pedogenesis and soil taxonomy. II. The soil orders. Developments in soil science. New York: Elsevier, 1983. v.11b, p.55-86.

HALL, G. F. \& OLSON, C. G. Predicting variability of soils from landscape models. In: MAUSBACH, M. J. \& WILDING, L. P. (Eds.). Spatial variabilities of soils and landforms. Madison, Wisconsin: Soil Science Society of America, 1991. p.9-24. (SSSA Special Publication; $\mathrm{n}^{\circ}$ 28).

HELIOS ENVIRONMENTAL MODELING INSTITUTE. HEMI. The Solar Analyst 1.0: User Manual, 2000. Disponível em: <http://www.hemisoft.com>. Acesso em: 12 abr. 2006.

IPPOLITI, R. G. A.; COSTA, L. M.; SCHAEFER, C. E. G. R.; FERNANDES FILHO, E. I. \& GAGGERO, M. R. Análise digital do terreno: ferramenta na identificação de pedoformas em microbacia na região de "Mar de Morros" (MG). Revista Brasileira de Ciência do Solo, v.29, p.269-276, 2005.
KÄMPF, N. \& SCHWERTMANN, U. Goethite and hematite in a climosequence in Southern Brazil and their application in classification of kaolinitic soils. Geoderma, v.29, p.27-39, 1983.

LAGACHERIE, P. \& VOLTZ, M. Predicting soil properties over a region using sample information from a mapped reference area and digital elevation data: a conditional probability approach. Geoderma, v.97, p.187-208, 2000.

LOTSPEICH, F. B. \& SMITH, H. W. Soils of the Palouse loess: I. The Palouse Catena. Soil Science, v.76, p.467-480, 1953.

McKENZIE, N. J. \& RYAN, P. J. Spatial prediction of soil properties using environmental correlation. Geoderma, v.89, p.67-94, 1999.

MITASOVA, H. \& HOFIERKA, J. Interpolation by Regularized Spline with Tension: II. Application to Terrain Modeling and Surface Geometry Analysis. Mathematical Geology, v.25, p.657-671, 1993.

MOORE, I. D. et al. Soil attribute prediction using terrain analysis. Soil Science Society of America Journal, v.57, p.443-452, 1993.

PACHEPSKY, Y. A.; TIMLIN, D. J. \& RAWLS, W. J. Soil water retention as related to topographic variables. Soil Science Society American Journal. Madison, v.65, p.1787-1795, 2001.

PHILLIPS, D. H. et al. Soil-landscape relationships at the lower reaches of a watershed at Bear Creek near Oak Ridge, Tennessee. Catena, v.44, p.205-222, 2001.

SCHWERTMANN, U. \& KÄMPF, N. Properties of goethite and hematite in kaolinitic soils of Southern and Central Brazil. Soil Science, v.139, p.344-350, 1985.

SOUSA JUNIOR, J. G. A. \& DEMATTÊ, J. A. M. Modelo digital de elevação na caracterização de solos desenvolvidos de basalto e material arenítico. Revista Brasileira de Ciência do Solo, v.32, p.449-456, 2008. 
TARDY, Y. \& NAHON, D. Geochemistry of laterites, stability of Al-goethite, Al-hematite, and $\mathrm{Fe}^{3+}$-kaolinite in bauxites and ferricretes: an approach to the mechanism of concretion formation. American Journal of Science, v.285, p.865-903, 1985.

THOMAS, A. L. et al. Predicting soil classes with parameters derived from relief and geologic materials in a sandstone region of the Vosges Mountains (Northeastern France). Geoderma, v.90, p.291-305, 1999.

TROEH, F. R. Landform parameters correlated to soil drainage. Soil Science Society of America Proceedings, v.28, p.808-812, 1964.

WILSON, J. P. \& GALLANT, J. C. Digital terrain analysis. In: WILSON, J. P. \& GALLANT, J. C. (eds.). Terrain analysis: principles and applications. New York: John Wiley \& Sons, 2000. p. 1-27.

ZHU, A. X. et al. Soil mapping using GIS, expert knowledge, and fuzzy logic. Soil Science Society American Journal, v.65, p.1463-1472, 2001.

ZIADAT, F. M. Analyzing Digital Terrain Attributes to Predict Soil Attributes for a Relatively Large Area. Soil Science Society American Journal, v.69, p.15901599, 2005. 